\title{
Enacting shared responsibility in biosecurity governance: insights from adaptive governance
}

\author{
Andrea Rawluk ${ }^{1}$, Ruth Beilin $^{1}$ and Stephanie Lavau ${ }^{1}$
}

\begin{abstract}
Amidst an increasingly complex global environment of trade and travel, with heightened concerns for the unintended or deliberate spread of species and diseases, biosecurity is a key policy goal in many parts of the world. In Australia, there is concern that invasive species (plants, animals, and diseases) enter, spread, and establish, threatening local industries such as agriculture, as well as human health and biodiversity. Shared responsibility for biosecurity is a recent policy direction that has gained great traction but requires improved conceptual and practical clarity in how local citizens are co-opted into or experience biosecurity programs. In this paper, we interrogate the framing and enactment of shared responsibility for biosecurity, propose a repositioning informed by attributes of adaptive governance that involves a clearer structuring of partnerships, and illustrate this through a case example of network-based, passive surveillance. This repositioning is organized around four pillars, where biosecurity is a part of dynamic cosmopolitan territories; enacted through diverse networks; integrating with existing types of knowledge, concerns, and practices; and forming networks of partnership. We consider implications for adaptive governance more generally, centering on structure, power, and decision making.
\end{abstract}

Key Words: adaptive governance; biosecurity; citizens in partnership; shared responsibility; social-ecological systems

\section{INTRODUCTION}

Amidst an increasingly complex, global environment of trade and travel, with heightened concerns for the unintended or deliberate spread of species and diseases, biosecurity is a key policy goal in many parts of the world. Biosecurity can be broadly understood as practices to prevent or respond to the introduction and proliferation of biological agents that are identified as threats to human health, animal health, ecosystems, and/or agriculture. These are reflected in the diversity of international obligations and agencies linked to biosecurity, including World Trade Organization agreements, the International Plant Protection Convention, the World Organization for Animal Health, and the World Health Organization.

A growing policy direction in biosecurity is to create "shared responsibility" across different sectoral stakeholders, and this presents both significant challenges and opportunities. Some research has investigated community and industry understandings of responsibility (e.g., Maller et al. 2007). Other studies have identified factors supporting communities' willingness to engage with shared responsibility (e.g., Curnock at al. 2017) as well as barriers to be overcome in dynamic and diverse landscapes (Sinclair et al. 2020). Practical interpretations of shared responsibility are often incoherent (Craik et al. 2017). Shared responsibility for biosecurity is a recent policy direction that has gained great traction but that requires improved conceptual and practical clarity in how local citizens are co-opted into or experience biosecurity programs. Focusing on improving passive biosecurity surveillance outcomes, we interrogate how shared responsibility is practiced in Australia and propose a conceptualization informed by adaptive governance that is centered on deliberately structured networks and relationships and understands the impetus for collaboration from the perspective of regulators and citizens involved in passive surveillance.

\section{SHARING RESPONSIBILITY FOR BIOSECURITY IN AUSTRALIA: DIRECTIONS, CHALLENGES, AND OPPORTUNITIES}

Biosecurity management is of increasing contemporary interest, predominantly underpinned by a "command and control" approach of focusing on the prevention and control of risk and determining what "belongs" and what must be excluded or removed (Graham et al. 2019). Australia, in its geographical isolation and relatively recent history of European settlement, gives considerable policy attention to the biological security of the nation state. This is initially grounded in a distinction between certain species as "native" to natural Australian landscapes and other species as "introduced" or "exotic" (Head and Muir 2004, Lavau 2011). Biosecurity in the Australian context is particularly concerned with the entry, spread, and establishment of those invasive species (plants, animals, and diseases) that threaten agricultural productivity, human health, and biodiversity (Simpson and Srinivasan 2014). Government investment has primarily focused on the protection of agricultural industries, seeking to maintain the quality of agricultural produce, and secure a freedom from pests and disease status to ensure access to international markets (Beale et al. 2008, Commonwealth of Australia 2015), despite most of these agricultural products themselves being alien to Australia. The costs of incursions can be considerable in terms of lost productivity, trade restrictions, and control efforts. There has also been renewed investment in "environmental biosecurity," to enhance the particular control of invasive animal pests and weeds that threaten biodiversity and ecosystem health (Commonwealth of Australia 2015).

Responding to these local and international concerns, the policy and practice of biosecurity in Australia has been changing, extending spatially, methodologically, and socially. First, there has been a shift from controlling the border to managing a continuum of offshore, border, and onshore activities (Beale et al. 2008, Simpson and Srinivasan 2014). 


\begin{abstract}
Quarantine has a largely negative, defensive connotation associated with isolation, segregation and disinfection at the border. Biosecurity is a more pro-active concept, aligned with the pre-, border, and post-border continuum, a multi-layered approach ... (Beale et al. 2008:xvii)
\end{abstract}

This has been accompanied by an increasing emphasis on techniques related to import risk analysis, certification, surveillance, and traceability (Beale et al. 2008, Commonwealth of Australia 2015). As has been remarked in other contexts, techniques of prevention are thus increasingly interleaved with techniques of precaution and preparedness, in shifting from an ideal of eliminating risk to a more pragmatic goal of managing risk (Anderson 2012, Bingham and Lavau 2012). As stated in an Australian review of biosecurity procedures, this represents "a shift from zero risk to managed risk, from barrier prevention to border management" (Beale et al. 2008:xvii).

These extensions to the spatiality and repertoire of biosecurity practice have been accompanied by a policy direction toward the redistribution and devolution of responsibility. A core recommendation of the 1996 national biosecurity review Australian Quarantine: A Shared Responsibility (Nairn et al. 1996), which was reaffirmed in the 2008 review One Biosecurity: A Working Partnership (Beale et al. 2008), was that biosecurity requires the contribution and coordination of government, industry, and community actors. "Effective biosecurity," it is elsewhere argued, "hinges on good governance of the institutions and actors involved in managing diseases and other risks" (Reed and Curzon 2015:33). This refrain, the need for partnerships between government, industry, and community, is likewise everpresent in biosecurity strategies in UK, USA, and elsewhere.

Yet, while the transition toward focusing on the sharing of responsibility is compelling, its conceptualization remains underdeveloped. In Australia, this emphasis on partnerships is frequently presented and managed as fulfilling the principles and practices of "shared responsibility" (e.g., Beale et al. 2008, Matthews 2011, Simpson and Srinivasan 2014). Shared responsibility is envisaged as an essential ingredient for effective biosecurity, for example, the equine influenza outbreak in the Australian Capital Territory in 2009 presented as where shared responsibility was needed to prevent the spread of this disease, but did not occur; and successful eradication of bovine tuberculosis and grapevine leaf rust as models demonstrating a successful shared responsibility approach (Gilmour et al. 2017). As a policy direction, shared responsibility is first invoked as a more cooperative relationship between Commonwealth, State, and Territories, in managing situations that transcend the geographical and political boundaries of their respective jurisdictions (Beale et al. 2008). Second, shared responsibility frames the devolution of certain post-border biosecurity practices to industry (Richards and Higgins 2016) and cost-sharing arrangements for post-border preparedness and response measures (Matthews 2011, Simpson and Srinivasan 2014). Third, and as addressed in this paper, shared responsibility frames the practice of community engagement as a one-directional "consultative approach that ... includes both commitment and obligation" (Beale et al. 2008:55). However, there are multiple, conflicting, and problematic interpretations of shared responsibility (Craik et al. 2017).
Concurrent with a "command and control" state of governance, the interpretation of sharing is manifest as an individualization of risk. Since the Second World War, shared responsibility has been interpreted as shifting responsibility from the nation state to individuals, which permeates biosecurity policy (Higgins et al. 2016) where "individuals [are] responsible for managing the risks faced by themselves and their families." (Hamilton 2014:453). Citizens are expected to take responsibility for their health, wellbeing, and prosperity and conversely are held responsible for misfortune (Beck and Beck-Gernsheim 2002; Kemshall 2001, as cited in Hamilton 2014). Such a push for individualized responsibility, away from a central government approach, has also been observed in natural resource management (Curtis et al. 2014). In the governing of biosecurity, it manifests the individualization of risk to citizens (Higgins and Dibden 2011) where "effective quarantine relies on all stakeholdersgovernments, industry and the general public - appreciating the importance of quarantine vigilance to everyday activities and responding accordingly" (Nairn et al. 1996:34).

Alongside this, the contemporary interpretation of responsibility is compliance, where the federal government sets ideals for biosecurity, and landowners are required to adhere to these ideals as standards. The relationship between pre-border, border, postborder, and market access is linear (Higgins and Dibden 2011, Commonwealth of Australia 2015). Responsibility for biosecurity devolves post-border to citizens (Richards and Higgins 2016). This means standardizing compliance so that individual farmers can be made accountable (Wallington and Lawrence 2008, Higgins et al. 2018). In the context of natural resource management, Davidson and Lockwood (2009) note that this compliance is reinforced in how citizens are engaged by government, yet the capacity of existing federal regulation in enforcing surveillance is limited (Commonwealth of Australia Government 2015). Consequently, government agencies expect or require citizens to exist in significantly undifferentiated ways to enable standard monitoring of biosecurity risk. Arguably this model needs to be modified to account for local judgements and multiple types of knowledge in order that on-ground, identified biosecurity risk, which may not conform to existing expectations within the model, are acknowledged.

The current approach to reinforcing compliance fractures relationships between communities and government and fosters distrust. The tools available to agencies tend to be limited and frequently punitive. For example, farmers and landowners can be fined if they report biosecurity incursions on their properties or in their practices (Donaldson 2008, Graham 2013). Local residents express concern with reporting a weed on their property for fear of facing such litigation: "Some landowners were reluctant to ask weeds officers for weed identification advice because they did not trust weeds officers to use their enforcement powers fairly" (Graham 2013:125). Palmer et al. (2009) identified similar issues of mistrust among livestock farmers in Western Australia. Compliance structures increase the divide between government and citizens, as opposed to encouraging closer relationships; citizens often mistrust and perceive governments as misusing power, and government has framed a dichotomous narrative of the good, responsible farmer, versus the bad, irresponsible farmer (Higgins et al. 2018). For monitoring to connect to sharing responsibility there needs to be a shared 
understanding of the purpose and trust within the community they are imagining to be monitoring (Beierle and Cayford 2002). The domineering "big stick" approach that compliance can easily be seen to represent can be understood as fracturing the wider intentions for biosecurity governance at local levels. Significantly, it also constructs or imagines particular internal community structures that would "connect" to such management aims.

Therefore, although the general community is noted as pivotal in shared responsibility for biosecurity (Beale et al. 2008:76), the conceptualization of who makes up community is homogenous and ambiguous (Kruger et al. 2010). Often, community is imagined just as farmers (Mooney 2008, as cited in Kruger et al. 2009). As well, there is the issue of who is excluded from bureaucratic versions of "community." The inclusion of traditional owners and managers (Falk et al. 2008), urban residents and diverse Landcare groups (De Chazal 2008), is not specifically captured in contemporary conceptualizations of community for biosecurity governance (Kruger et al. 2010). If community is the political space or territory of shared responsibility, then some attention must be paid to how it operates, is structured, and sustained — not as a rigid formulation -but as flexible, diverse relationships responding purposefully to risk. To capture these dynamic and political assemblages of relationships central to shared responsibility enacted both across networks and on-ground, here we pivot away from the policy and literature focus on "community" in biosecurity, to territoriality (Brenner 1999, Allen and Cochrane 2007).

\section{TURNING TO ADAPTIVE GOVERNANCE TO INFORM THE PRACTICE OF SHARED RESPONSIBILITY}

Based in social-ecological systems thinking, adaptive governance reflects "a dynamic link between social and ecological landscapes that recognizes the complexity of ecological systems, inherent uncertainty, and unknown feedbacks stemming from social actions taken to manage ecological resources" (Chaffin et al. 2014). Challenges, such as biosecurity, are a part of highly interconnected and irreducible social and ecological domains that are continuously dynamic and that comprise multiple, connected, and nested scales (Gunderson and Holling 2002). The conventional natural resource management paradigm of command and control (Holling and Meffe 1996) aligns with a parallel ethos around biosecurity, such as assuming that biosecurity can be managed as the patrolling of a border. By contrast, adaptive governance recognizes dynamism as inherent to a social-ecological system and such systems need to be holistically managed (Chaffin et al. 2014) but cannot be controlled in a mechanistic fashion. The highly adaptive character of invasive species, for example, can be met with an approach of territoriality that is centered on networks of partnerships such as the public, and replaces the more commonly used, and vaguely employed, language targeting citizens in general.

Adaptive governance works across scales to create a multilevel structure. Adaptive governance "theoretically culminates in coordination at a bioregional scale, a scale at which the governance structure best fits ecological function" (Chaffin et al. 2014). Partnerships in governance are similarly connected through social networks across different scales from local level, to broad, cross-border, and global scales (Armitage 2007). For example, infestations or landscape processes can challenge spatial scale because infestations often challenge previously recognized geographic borders, with recent examples of how flying foxes or fire cross state lines (Tidemann and Vardon 1997, Piper 2020). This tiered approach to governance can be horizontally linked across organizations and citizens (Pritchard and Sanderson 2002). In the face of complex, transborder social-ecological challenges, such as biosecurity, there is a need to define the relevant territory within the landscape so as to map the dynamic and interconnected governance that mobilizes participants and builds partner networks.

Shared understanding of a management challenge and the recognition of local knowledge ideally underpin adaptive governance, relying on and augmenting the social capacity of individuals, institutions, and society (Folke et al. 2005, Rawluk et al. 2020). This involves sharing knowledge, and learning; and central to it is the collaboration across partnership networks (Armitage et al. 2009). The knowledge and expertise of local people are recognized (Gadgil et al. 1993) and integrated within multiple knowledge systems (Ludwig et al. 2001). Local knowledge is integrated as part of multiple knowledge systems (that include expert and traditional knowledge) and this underpins flexible governance (Berkes 2009) that can support social-ecological justice (Collard et al. 2018). However, integrating multiple types of knowledge in practice can pose challenges, such as working across ontological, epistemological, and practical differences.

In the conceptualizing of biosecurity that underpins this paper, the sharing of responsibility is situated as a recognized political territory in which "government at a distance" (from the central state) occurs (Welsh 2014:16). Our adaptive governance focus is not oriented to society as a whole, but the variations within the political construction of these biosecurity territories. These territories are the location of partnership networks, which, as Harrington et al. (2008) proposes, encompass a typology of community, or a relational assemblage in territory (Briassoulis 2017). Such networks can be the focus of government agency collaboration for biosecurity management in which instrumentalist evocations suggest that participation is possible with the right skills and training across both public and private land: farmers with the skills to recognize pathogens or weeds; private residents with the skills to observe incursions on their properties or local landscapes; and volunteers in public or private spaces. The active involvement of such participants in adaptive governance means on one hand, that actions must emerge from within the "local" or at a granular relational level, and on the other, that this involvement must be harnessed for the cause of biosecurity management. For example, Reid et al. (2020) showed that in a bushfire context, sharing responsibility in local networks operates through clear and structured organization and every opportunity for mobilization and collective action flexes the muscles for response. The networks and relationships that were formed through long-term mobilization provided experience for a community in resisting a toxic dump site, keeping the train service running to their town, and operating a farmers' market for tourists over many years. These enabled a structured organizational response to mobilizing for fire. Adaptive governance requires flexible institutional support and informal learnings need to be shared. Clear and organized structures enable participation in and engagement with biosecurity practices (Curnock et al. 2017). 
Adaptive governance can organize around formal, clear structures for partnering, as well as informal and atomistic responses because of the behavioral reality of individuals responding to risks in dynamic social-ecological systems.

Adaptive governance is organized through formal and informal networks (Österblom and Folke 2013) of knowledge sharing and decision making. These networks are necessarily diverse (Newman and Dale 2005) and formed and maintained as ongoing relationships fostering flexibility and responsiveness to disturbance (Lebel et al. 2006, Chaffin et al. 2014). Olsson et al. (2006) also note the importance of formal and informal networks for information flow in slow or rapid social-ecological change. There are epistemic networks that support the sharing of knowledge and there are shadow networks that are self-organizing in the event of rapid change or crisis and provide "a willingness to experiment and generate alternative solutions to emerging problems" (Olsson et al. 2006). Building relationships and trust within citizen networks and with government is critical (Doubleday 2007, Chaffin and Gunderson 2016). Close, integrative relationships can enable the better transfer of information and ideas and the flexible capacity to adapt and respond to uncertainty (Paschen and Beilin 2015).

At the intersection of territory and shared responsibility in adaptive governance is the dynamic thread of power. Although central to examinations of territoriality (e.g., Allen and Cochrane 2007), it is emerging, but has been considered in less depth and conceptual nuance in adaptive governance (Cote and Nightingale 2012). Cleaver and Whaley (2018) argue for critical institutionalism that centers on the process, power, and meaning in developing institutional arrangements that are appropriate to context. Van Assche et al. (2017) explore materiality through knowledge/power in livelihoods, which echoes networks-ofpractice. Repositioning shared responsibility in adaptive governance will require a deliberate consideration of power.

\section{REPOSITIONING SHARED RESPONSIBILITY THROUGH ATTRIBUTES OF ADAPTIVE GOVERNANCE}

We draw on attributes of adaptive governance to reframe shared responsibility for biosecurity, in which it is,

(i) a part of dynamic cosmopolitan territories;

(ii) enacted across diverse networks;

(iii) integrating existing types of knowledge, concerns, and practices; and

(iv) forming partnership networks.

Although much scholarship on shared responsibility has focused on its use for emergency circumstances, this repositioning of shared responsibility emphasizes governance as a day-to-day process, and risk as a continuum. The building and maintenance of relationships require different attention related to where actors are in the risk cycle of emergency across the landscape (Sharp et al. 2013, Reid et al. 2020).

\section{(i) A part of dynamic cosmopolitan territories}

There is a growing call for integrated forms of biosecurity management (Spring and Kompas 2015, Hester and Cacho 2017) that better acknowledge the complexity of landscape contexts, such as multiple land uses and stakeholders of multifunctional landscapes (Sinclair et al. 2020). Counter to the contemporary view that sees exclusion and domination of life forms based on nativeness or economic contribution (Rabinow and Rose 2006, Lavau 2011, Anderson 2012), where certain species are considered either good or bad and subsequently accepted or excluded, socialecological systems thinking fosters a more entangled and holistic view.

Building on social-ecological systems thinking, the philosophy of a cosmopolitan territory is founded on inclusivity and the diversity of humans (and non-humans), "towards (Kant's) perpetual peace housed in the virtues of a globally democratic citizenship" (Doran 2009:175). As a counter to the public/private division of property (Hardt and Negri 2009), cosmopolitanism and landscape of relationship sees the cooperation of people for a greater good (Campbell 2010). Accepting that landscape comprises a continuously changing array of life (e.g., Barker 2010, Reo et al. 2017), including through complex political arrangements, connects biosecurity decision making to the everyday decision practices of both public and private landscape managers (D'Emden et al. 2004). Diverse cosmopolitan territories embrace the dynamics of many social drivers in the system, such as multiple social values, cultures, and land uses as well as different species shaping the provision of ecosystem services and inhabiting of places.

An example of a cosmopolitan view of territory is recognizing that beekeepers locate their hives of European bees in national parks for the winter in Australia. These non-indigenous species can provide co-benefits and pollination services as opposed to being regarded through a good-bad binary as invasive (Anderson 2012, Edwards et al. 2018). A reframing of biosecurity as a socialecological context in cosmopolitan territories leads to the need for a clearer understanding of the multiple levels of governance and communities engaged in navigating these terrains. Further, it clarifies the spatialities and contexts in which territories are defined, responsibility is shared, and for who, why, and with what goals.

\section{(ii) Enacted across networks of diversity}

Participants connected to biosecurity are increasingly diverse and co-existing bio-regionally in multifunctional rural landscapes (Sinclair et al. 2020). To conceptualize the diversity of networks within biosecurity territories, we draw on the Harrington et al. (2008) typology in a more flexible and tailored way: partnershipsin-particular and partnerships-in-general. Partnerships-inparticular incorporate the five community concepts of the typology and can be first identified as pre-existing networks of individuals, connected through place, practice, or interest, but are also welcoming to new groups or individuals. For biosecurity, partnerships-in-particular could take on many forms, such as partnerships of interest (e.g., beekeepers, hobby farmers, bird watchers) or communities of practice (e.g., primary producers such as farmers; Harrington et al. 2008). Accompanying an acknowledgement of multiple kinds of partners and networks that can be engaged in different ways for surveillance, is a recognition that rural and regional areas have a plurality of interests, such as economy, lifestyle, recreation, and property rights, and diverse social values (Mendham and Curtis 2010). Partnerships-in-general describes members of the public who are not connected through place, practice, or interest, and who are not captured in the Harrington et al. (2008) typology because they 
are unaffiliated with an interest group, practice, or place. Conceptualizing partnerships as in-general and in-particular has implications for how surveillance options are best approached for adaptive governance, such as what forms of engagement would be most appropriate and accessible to different types, the different motivations, knowledge, and skills that they bring, and how to form relationships between government and partnership networks to support resilience. Awareness of and attendance to the diversity of community types, as well as interests and priorities, can avoid marginalizing types of communities that might otherwise be forgotten in engagement for natural resource management (Harrington et al. 2008).

In this diversity, multiple and seemingly redundant networks are essential to ensuring that data collection is maintained in the event that a network ceases or many members of one network are no longer able to be involved (Walker and Salt 2006). Multiple surveillance networks, gathering different kinds of knowledge, would provide coherence in adaptive biosecurity governance.

Bridging policy-level directives to an on-the-ground understanding then begins with a careful process of shared identification of relevant partnership networks and organizing appropriate forms of engagement workshops to negotiate, develop, and design surveillance methods jointly. Building and maintaining networks of diversity requires clearly understanding who participates as biosecurity partners (Kruger et al. 2009). "Effectively identifying, analysing and systematically representing stakeholders [citizens in partnership networks] is crucial to the design of participation and communication strategies to improve biosecurity" (Reed and Curzon 2015:19). Different partnership networks could be identified through different stakeholder mapping processes, including normative, instrumental, and descriptive stakeholder mapping (Reed and Curzon 2015). Shared responsibility requires a clear definition of who is engaged and a rigorous identification of which partnership networks are relevant to a particular context.

\section{(iii) Integrating existing types of knowledge, concerns, and practices}

Integrating the diversity of networks also brings a diversity of knowledge and practices. The day-to-day practices and knowledge of citizens (and members of a network) are central to the enactment of surveillance. Cook and Waagenar (2012) argue that practice and knowledge are intimately entangled and cyclically connected. Taking a more practice-oriented approach acknowledges the experiences and interpretations of, for example, hobby beekeepers who observe the hives that they tend with attention and awareness of the possible threat and incursion of the varroa mite in their territory (Phillips 2014). Centering on practice enables participants across partnerships-in-particular, including both professionals and hobbyist - poultry farmers and hobby poultry-keepers - to observe an incursion of disease on their property or in their flock. For example, farmers demonstrate knowledge through skilled craftwork in maintaining the health of their animals and in turn supporting biosecurity (Higgins et al. 2018). How these network members engage, hands-on, in their practices shape what they see and know about their professional or hobby interest in their hive, herd, orchard, or flock, but it also shapes how they see the world more broadly. As such, multiple understandings of reality (Guba and Lincoln 1998), what can be known, and what is important will inherently come to the forefront through aligning adaptive governance with a bottomup and integrated reframing of shared responsibility.

Shared responsibility involves on-ground approaches for reconciling multiple knowledges and ontological differences for problem and context definition. These practices must ensure mutual respect and multiple voices to assist in recognizing the multiple forms of knowledge that are frequently competing in these territories. A first aspect of reconciling multiple knowledges is in partnership network-centered problem definition and negotiating the meaning of biosecure territories and sharing responsibility (Barker 2010, Reo et al. 2017). In this negotiation, policy makers, industry, and the diversity of relevant participants need to consider the following: What targets or issues of concern are okay to be present? What life forms should be absent? To what levels are certain life forms considered tolerable? Critically engaging with these questions could lead to a reframing of what a "threat" is and for whom. For example, what is a threat to some, could be valuable to another. In Australia, the floriferous Echium species (Paterson's Curse/Salvation Jane) have a reputation as a biosecurity threat and weed species that can be poisonous to some stock (Nordblom et al. 2001), earning the moniker Paterson's Curse. Yet they can also provide crucial nutrition to certain animals in drought conditions (Agriculture Victoria 2018) and be a source of food for honeybees, thus celebrated as Salvation Jane. In creating a shared definition and understanding of biosecure territories in particular contexts, there can be an adjustment of perceived threat, from that which warrants eradication to a life form that can be monitored, controlled, and understood through on-ground practices.

Repositioning shared responsibility involves sharing practices and respects multiple knowledge systems as legitimate. Integrating passive surveillance, and local knowledge, in the broader biosecurity system will require negotiation of shared understanding across multiple practice assumptions (Carrozza 2015, Reed and Curzon 2015) and multiple worldviews (Berkes et al. 2003). Doing so can be facilitated through critically reflecting on what is practiced and known (Rawluk et al. 2020). Bridging multiple ways of knowing in biosecurity surveillance-from broad-level policy making, based on science-based bioeconomic modeling and quantitative data to on-ground observation among professionals and enthusiasts, based on the knowledge and expertise of local people - echoes challenges in interdisciplinary research and work. Studies in interdisciplinarity argue for practices that clarify understanding, language, and assumptions of reality (Bracken and Oughton 2006, Phoenix et al. 2013, Jalbert and Kinchy 2016), as well as reinforcing trust-building (Bracken and Oughton 2006) and the co-creation of shared ideas (Star 2010) and understandings (Rawluk et al. 2020). In negotiating an understanding of biosecure territories and shared responsibility, citizens, as passive surveillance network members, are entitled to knowledge rights (Jasanoff et al. 2004). They are "knowledgeable... with the right to challenge policy decisions, participate, and offer expertise" (Carrozza 2015:113). This shared understanding needs to be revisited as necessary through time to be meaningful across levels of governance from activists to policy partners (Enticott 2014, Curnock et al. 2017). The processes that must be engaged in multi-level governance of shared responsibility are not prescriptive and are tailored and meaningful to the partnerships 
in-particular or in-general that are relevant to each biosecurity context.

As the complexity and dynamism of this reframing of shared responsibility and biosecurity becomes greater, so too does the need to pay attention to the quality of participation and manage issues of power and conflict as part of the design of governance. Dreyer et al. (2014) present the inclusivity-effectiveness dilemma in governance, wherein a higher number of participants involves more views and in turn more conflicts are likely. Local knowledge arises from within social-ecological relational knowing, such that the emergent culture is the dynamic substance of participatory politics (Carrozza 2015). Fresh thinking on process design is imperative (Dreyer et al. 2014). Active knowledge-production and affirmation across multiple networks, knowledges, and relationships will require skill and facilitation for navigating conflict and power dynamics, and for individuals to act for the greater good (Doubleday 2007). However, rhetoric is not enough; just the acknowledgement that local knowledge exists, or that cogovernance can be more effective, does not ensure legitimacy of democratic outcomes. Attention must be directed to the quality of the engagement, the processes that ensure peoples' voices are heard, and similar affirmations of transparency. In summary, a reframing of practice and method involves focusing first on local practices and enmeshing these in biosecurity efforts so that these practices shape the multiple knowledges involved (Rawluk et al. 2020). Further integrating these with insights from interdisciplinarity studies, and with processes for navigating power dynamics and conflict then become part of the capacity and relationship building that supports sharing responsibility.

\section{(iv) Forming networks of partnership}

Networks of partnership (in-particular and in-general) must be mapped, structured, and supported across governance through both commitment and compliance of the shared understanding of biosecurity. Biosecurity is defined, negotiated, and enacted in overlapping and interwoven formal and informal networks (Sinclair et al. 2020). These multiple and overlapping networks are dynamic relationships of information gathering, knowledge sharing (Walker and Salt 2006, Crona and Parker 2012), and mobilization (Leach and Scoones 2007, Graham 2013) as a "constitutive process in which particular concepts of the public are [activated], negotiated, and enacted" (Barnes et al. 2004:273). Although decision making is devolved and dispersed across networks (Lockwood et al. 2010), in this enactment of networks of partnership, members engage in a contract of duty, which can assert mutual expectations of commitment and obligation.

Networks can either be pre-existing or self-organizing. For example, a volunteer-driven sustainability organization, like Landcare in Australia (Woodhill 2010), could be a pre-existing network that could be further developed. Within these networks, trusted sources of knowledge can be mobilized to support action and surveillance, such as through the well-recognized research organization CSIRO in Australia, which provides guides for local identification of bugs in the garden and for recognizing the biodiversity value of non-indigenous flora (Beilin and Hunter 2011). Similar sources can be utilized by different networks of communities in-particular or in-general training or tasks. Adaptive and collaborative governance for biosecurity is thus enacted in communities (Birnbaum 2016) through their practices and involve framing the problem, learning, and sharing knowledge.

Clear articulation and structuring of shared responsibility are needed to transcend a broader policy level and on-ground understanding. At a policy level, a clear depiction is needed for supporting flexible preparation and responses to questions including who does what and in what context; how surveillance activity is funded; how success of the surveillance is to be monitored; and how and what social learning occurs to increase the adaptive strengths of the partnership networks. As a democratic process, the relationships and interconnections within and between networks and government must be transparently "managed so that benefits, burdens, and responsibilities are unambiguous and negotiated" (Lockwood et al. 2010:989). Support at a federal or state level can be crucial to financially and logistically building and supporting key relationships (Chaffin and Gunderson 2016). The policy-level assumption of shared responsibility as a clear and unambiguous concept outside the policy sphere has proven to be unfounded. It is, rather, what McLennan and Handmer (2014) describe, in the case of shared responsibility and disaster risk management, as a half empty contract. Government can desire compliance and participants can experience the obligation without understanding what is expected, how they are obligated or how to respond. We argue that shared responsibility will work best with a mutual commitment to action, and it is possible to conceive of government-partner oriented contracts consolidated through the validation of relationships between different partnership networks and empowered agencies. The contract of shared responsibility in biosecurity needs to be brought to life in meaningful and negotiated ways. Ravetz (1990), as cited in Carrozza (2015), argues that ideally, sharing responsibility is an expression of democracy that also involves an ongoing renewal of a social contract between science and society. The terms of the contract must be meaningfully agreed.

\section{PRACTICE-ORIENTED CASE STUDY: EXPLORING THE IMPLICATIONS OF SHARING RESPONSIBILITY FOR PASSIVE SURVEILLANCE}

To explore what the repositioning of shared responsibility could look like, we conceptually draw on a hypothetical and practiceoriented example of passive surveillance in cosmopolitan landscape territories. Surveillance comes in multiple forms, primarily active surveillance and passive surveillance. Much scholarship focuses on active surveillance, which tends to be modeled as expert knowledge, science-based, and conducted by professionals at federal borders through testing and observation (e.g., Kompas et al. 2019). Passive (or general) surveillance is typically carried out by members of the public through a multitude of approaches, such as detection hotlines (Department of Agriculture 2021) and interest or economic-based stakeholder networks (Perrone and Malfroy 2014) that are the "eyes and ears" of government positioned on the ground, such as hobbyists as well as professionals. These local participants represent a breadth of knowledge and expertise that can differ from the science and command and control-based model of active surveillance. However, much like shared responsibility generally, there is little conceptual clarity of what passive surveillance is and how it is enacted. Most notably, passive surveillance has been typically utilized to enact top-down, government priorities. In our 
repositioning of shared responsibility, passive surveillance is reimagined as a part of a dynamic cosmopolitan territories; enacted across diverse networks; integrating with existing types of knowledge, concerns, and practices; and forming partnership networks that in turn can be useful in providing data to the active surveillance modelers.

Passive surveillance thus is a part of a complex, dynamic system. This system shapes the species in it and is shaped by them. Recognizing the complexity of these cosmopolitan territories means that passive surveillance networks engage with the uncertainty inherent in systems and accept that each individual has a limited or focused view that shapes observational understanding. Dynamic cosmopolitan territories do not exist in a binary of "inclusion" and "exclusion", "native" and "non-native." Building on Barker (2010), citizens in partnership networks engage with complexity through taking part in negotiating and shaping a collective understanding of the boundaries for including and excluding lifeforms (Rawluk et al. 2020). For example, hobby gardeners and professional orchardists might develop a shared and negotiated understanding of fruit fly incursion. Citizens in partnership networks critically reflect on what is considered a part of their landscape, and what is considered an incursion, and why, such as the earlier example of honeybees, and where they belong and why. The different partner networks involved need to collaboratively identify what information will be gathered in surveillance and develop an approach to do so, in order to foster learning and a shared understanding of their involvement (Bouwen and Taillieu 2004, Jasanoff et al. 2004).

Guided by principles of transparency and accountability, this sharing can be enacted across partnership networks through carefully facilitated focus groups, workshops, and collaborative management practices common in adaptive co-management that capture the diversity of networks that are territorially present (e.g., Armitage et al. 2009, Rawluk et al. 2020). Critically engaging with the history of these social-ecological systems, the forces of colonialism and productivist landscapes need to be considered in determining what to surveille and how. Determining what "belongs" is a perennial political question that needs to be critically and continually revisited.

Passive surveillance networks will be overlapping and carrying out redundant surveillance pathways (Walker and Salt 2006), which in systems thinking acts to strengthen system resilience. Partnershipsin-particular could be practiced through networks of people in a particular place, such as residents of a particular area or Landcare groups, as well as networks of people with a shared practice, such as professional and hobby farmers or beekeepers, alongside networks of people with a shared interest, such as birdwatchers or environmentalists. These partnerships-in-particular can be combined within partnerships-in-general, such as general public campaigns and approaches like the detection hotlines mentioned earlier. For example, in the context of fruit fly incursions in Australia, which exist in complex human and non-human landscapes (Phillips 2013), different partnership-in-particular networks could be essential to identifying and monitoring a fruit fly incursion, such as networks of professional horticulturalists as well as lifestyle property owners engaged through different, preexisting interest groups. Similarly, the concern of a varroa mite incursion among honeybees could draw on multiple networks of partnerships-in-particular with overlapping interests, such as a network of professional beekeepers and BeeForce, which builds on the expertise of pre-existing hobby and small-scale beekeepers (Perrone and Malfroy 2014). Enacting passive surveillance across diverse territories means clearly mapping and encouraging different partnership networks in the landscape.

We visually depict the overlapping surveillance networks within a multi-level, adaptive governance framing for biosecurity in Figure 1. As a democratic process, we re-assert that the enactment of these relationships be transparently "managed so that benefits, burdens, and responsibilities are unambiguous and negotiated" (Lockwood et al. 2010:989). This management begins within these purposeful partnerships that are co-designing or co-managing the delineation of the biosecurity risk territories. These will benefit from facilitation or support by local government agencies or networked levels of state and federal officers. Providing support to develop and maintain multiple, overlapping passive surveillance partnership networks will enable local people within cosmopolitan territories to be involved and share responsibility for biosecurity.

Forming networks of partnership enables communication, commitment, and mobilization in passive surveillance. These networks can be purposefully organized and structured and operate out of commitment not just compliance. Counter to the status quo, where historically their surveillance would put them at risk of litigation (Graham 2013), their participation might rather be about relationship building through multi-level governance that encourages them to act because they understand their views and concerns to be heard and see themselves as part of biosecurity solutions. Concurrently, these networks, centered on critical reflection and relationships, would mean that partners could mobilize to change direction in policy and priorities for biosecurity through their observations and practices. Doing so reflects shifting to a concurrent bottom-up approach to governance, where these diverse passive surveillance networksresidents, farmers, birdwatchers, beekeepers, Landcare groups, government agencies, scientific operatives - could share their observations and ideas.

\section{IMPLICATIONS FOR ADAPTIVE GOVERNANCE IN BIOSECURITY RISK}

Sharing responsibility in biosecurity highlights the need for adaptive governance to identify and structure networks of partnership that can both formalize surveillance and re-center the distribution of power through co-design and management of adaptive governance. First, while adaptive governance scholarship has focused on the importance of members of the public in governance, little attention has been given to clearly identifying the networks and partnerships that compose the territory. By re-imagining the spatial and temporal territories of biosecurity risk, and locating partner networks within them, passive surveillance changes to emphasize knowledge-sharing, adaptive relationships, coherent views of risk, and turns compliance toward commitment. This bottom up, flexible, and co-designed management of biosecurity risk will undoubtedly encounter roadblocks because of the circuitry of power (Clegg 1989, Armstrong 2019). The focus on connectivity and power circulations in adaptive governance extends the conceptualization of collective action in invasive species control as externally led, 
Fig. 1. Organization of multi-level governance and surveillance in a reframing of biosecurity. Multiple partnership networks-inparticular will overlap to observe and gather knowledge about a biosecurity context through passive surveillance. These surveillance networks are linked through local organizations that connect partnerships-in-particular that are precisely mapped and structured.

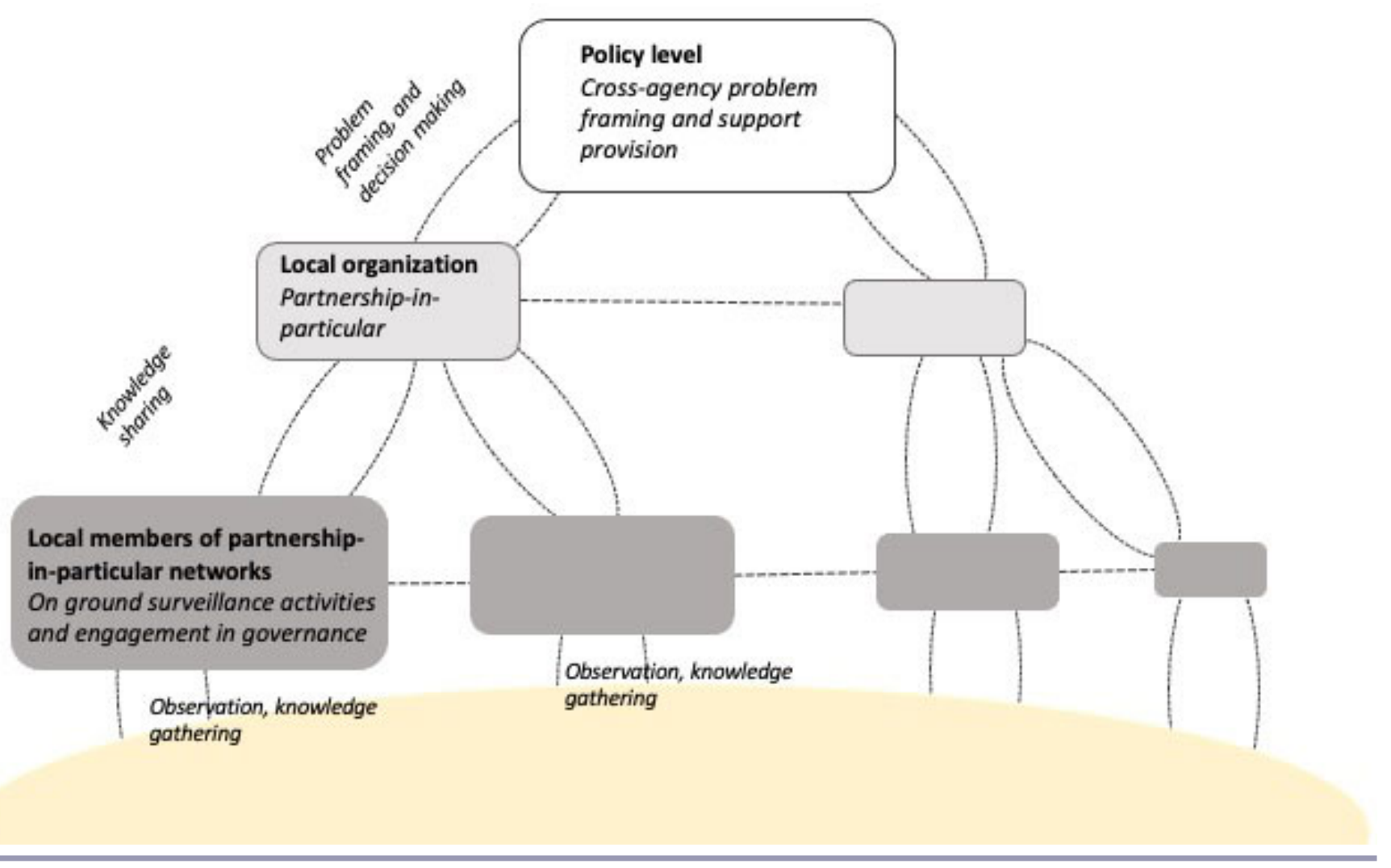

citizen-led, co-managed, and organizational coalitions (Graham et al. 2019).

Reframing shared responsibility through adaptive governance redirects community engagement practices to echo the relational turn in navigating complex challenges (Beilin and Paschen 2020, West et al. 2020), and focuses on connection, learning, and practice-change through networks of partnership. Practices in these networks of partnership can draw on community engagement for disaster preparedness as a starting point, such as the bottom up approach developed by Bogdan et al. (2021) for building social capital, challenge citizens' understanding in order to foster the development of new knowledge and learning, and develop a new way of preparing for change. Shifting to practicebased approaches for navigating complex challenges through networks of partnership, means that experience of citizens can be engaged and integrated to pivot "to more unruly and emergent approaches, where the "uncontainable" aspects of the world are embraced as sources of ongoing learning and transformation" (West et al. 2019:549). Practices for engaging with citizens for adaptive governance need to be focused on ongoing relationships that draw on the experiences of citizens and enable networks to do what they do differently.

\section{CONCLUSIONS}

In the dynamic space of adaptive governance within complex social-ecological challenges and our every-changing world, there is a growing need for structured and dynamic partnerships and their networks, to observe, monitor, and surveille change in territories, and also create change in accordance with social and cultural directions. Adaptive governance can be both a mechanism for reinforcing and refining the status quo, and also, through critical consciousness and mobilization, an opportunity to create and support dynamic preparedness and response to landscape risk. An evolution of shared responsibility to enable partnerships-in-particular and partnerships-in-general to be better and more connected - for information gathering, meaning acquisition, and decision making and policy definition and support-requires more than mobilization of possible partners. It requires acknowledging the connectedness of citizens as active contributors involved in relational structures that define the dynamic biosecurity territory and its adaptive governance. This purposeful and mutual engagement among government agencies and others in the mapped and structured partnership networks will make shared responsibility for biosecurity meaningful and based on duty rather than compliance and opens many opportunities for the contemporary enactment of adaptive governance.

Responses to this article can be read online at: https://www.ecologyandsociety.org/issues/responses. php/12368 


\section{Acknowledgments:}

We wish to acknowledge and express gratitude to Professor Tom Kompas who funded some research that was built on in crafting this paper.

\section{Data Availability:}

Not applicable to our manuscript.

\section{LITERATURE CITED}

Agriculture Victoria 2018. Paterson's curse. Agriculture Victoria, Australia. [online] URL: http://agriculture.vic.gov.au/agriculture/ pests-diseases-and-weeds/weeds/a-z-of-weeds/patersons-curse

Allen, J., and A. Cochrane. 2007. Beyond the territorial fix: regional assemblages, politics and power. Regional Studies 41 (9):1161-1175 https://doi.org/10.1080/00343400701543348

Anderson, B. 2012. Affect and biopower: towards a politics of life. Transactions of the Institute of British Geographers 37 (1):28-43. https://doi.org/10.1111/j.1475-5661.2011.00441.x

Armitage, D. 2007. Governance and the commons in a multi-level world. International Journal of the Commons 2(1):7-32. https:// doi.org/10.18352/ijc. 28

Armitage, D. R., R. Plummer, F. Berkes, R. I. Arthur, A. T. Charles, I. J. Davidson-Hunt, A. P. Diduck, N. C. Doubleday, D. S. Johnson, M. Marschke, P. McConney, E. W. Pinkerton, and E. K. Wollenberg. 2009. Adaptive co-management for socialecological complexity. Frontiers in Ecology and Environment 7 (2):95-102. https://doi.org/10.1890/070089

Armstrong, S. 2019. Power shift: the longest revolution. House of Anansi, Toronto, Ontario, Canada.

Barker, K. 2010. Biosecure citizenship: politicising symbiotic associations and the construction of biological threat. Transactions of the Institute of British Geographers 35(3):350-363. https://doi.org/10.1111/j.1475-5661.2010.00386.x

Barnes, M., J. Newman, and H. Sullivan. 2004. Power, participation, and political renewal: theoretical perspectives on public participation under New Labour in Britain. Social Politics 11(2):267-279. https://doi.org/10.1093/sp/jxh034

Beale, R., J. Fairbrother, A. Inglis, and D. Trebeck. 2008. One biosecurity: a working partnership. The independent review of Australia's quarantine and biosecurity arrangements. Report to the Australian Government, Canberra, Australia.

Beck, U., and E. Beck-Gernsheim. 2002. Individualisation. SAGE, London, UK.

Beierle, T., and J. Cayford. 2002. Democracy in practice: public participation in environmental decisions. Resources for the Future, Washington, D.C., USA.

Beilin, R., and A. Hunter. 2011. Co-constructing the sustainable city: how indicators help us "grow" more than just food in community gardens. Local Environment 16(6):523-538. https:// doi.org/10.1080/13549839.2011.555393
Beilin, R., and J.-A. Paschen. 2020. Risk, resilience and responseable practice in Australia's changing bushfire landscapes. Environment and Planning D: Society and Space https://doi. org/10.1177/0263775820976570

Berkes, F. 2009. Evolution of co-management: role of knowledge generation, bridging organizations and social learning. Journal of Environmental Management 90(5):1692-1702. https://doi.org/10.1016/ j.jenvman.2008.12.001

Berkes, F., J. Colding, and C. Folke. 2003. Navigating socialecological systems: building resilience for complexity and change. Cambridge University Press, Cambridge, UK. https://doi. org/10.1017/CBO9780511541957

Bingham, N., and S. Lavau. 2012. The object of regulation: tending the tensions of food safety. Environment and Planning A: Economy and Space 44(7):1589-1606. https://doi.org/10.1068/ a44394

Birnbaum, S. 2016. Environmental co-governance, legitimacy, and the quest for compliance: when and why is stakeholder participation desirable? Journal of Environmental Policy \& Planning 18(3):306-323. https://doi.org/10.1080/1523908x.2015.1077440

Bogdan, E. A., A. M. Roszko, M. A. Beckie, and A. Conway. 2021. We're ready! Effectiveness of community disaster preparedness workshops across different community groups in Alberta, Canada. International Journal of Disaster Risk Reduction 55:102060. https://doi.org/10.1016/j.ijdrr.2021.102060

Bouwen, R., and T. Taillieu. 2004. Multi-party collaboration as social learning for interdependence: developing relational knowing for sustainable natural resource management. Journal of Community \& Applied Social Psychology 14(3):137-153. https:// doi.org/10.1002/casp.777

Bracken, L. J., and E. A. Oughton. 2006. 'What do you mean?' The importance of language in developing interdisciplinary research. Transactions of the Institute of British Geographers 31 (3):371-382. https://doi.org/10.1111/j.1475-5661.2006.00218.x

Brenner, N. 1999. Beyond state-centrism? Space, territoriality, and geographical scale in globalization studies. Theory and Society 28 (1):39-78.

Briassoulis, H. 2017. Response assemblages and their socioecological fit: conceptualizing human responses to environmental degradation. Dialogues in Human Geography 7 (2):166-185. https://doi.org/10.1177/2043820617720079

Campbell, F. K. 2010. Crippin' the flâneur: cosmopolitanism, and landscapes of tolerance. Journal of Social Inclusion 1(1):75-89. https://doi.org/10.36251/josi.6

Carrozza, C. 2015. Democratizing expertise and environmental governance: different approaches to the politics of science and their relevance for policy analysis. Journal of Environmental Policy \& Planning 17(1):108-126. https://doi.org/10.1080/1523908X.2014.914894

Chaffin, B. C., H. Gosnell, and B. A. Cosens. 2014. A decade of adaptive governance scholarship: synthesis and future directions. Ecology and Society 19(3):56. https://doi.org/10.5751/ES-06824-190356 
Chaffin, B. C., and L. H. Gunderson. 2016. Emergence, institutionalization and renewal: rhythms of adaptive governance in complex social-ecological systems. Journal of Environmental Management 165:81-87. https://doi.org/10.1016/j.jenvman.2015.09.003

Cleaver, F., and L. Whaley. 2018. Understanding process, power, and meaning in adaptive governance: a critical institutional reading. Ecology and Society 23(2):49. https://doi.org/10.5751/ ES-10212-230249

Clegg, S. R. 1989. Frameworks of power. SAGE, London, UK. https://doi.org/10.4135/9781446279267

Collard, R.-C., L. M. Harris, N. Heynen, and L. Mehta. 2018. The antinomies of nature and space. Environment and Planning E: Nature and Space 1(1-2):3-24. https://doi.org/10.1177/251484$\underline{8618777162}$

Commonwealth of Australia. 2015. Agricultural competitiveness white paper: stronger farmers, stronger economy. Commonwealth of Australia, Canberra, Australia.

Cook, S. D. M., and H. Wagenaar. 2012. Navigating the eternally unfolding present: toward an epistemology of practice. American Review of Public Administration 42(1):3-38. https://doi. org/10.1177/0275074011407404

Cote, M., and A. J. Nightingale. 2012. Resilience thinking meets social theory: situating social change in socio-ecological systems (SES) research. Progress in Human Geography 36(4):475-489. https://doi.org/10.1177/0309132511425708

Craik, W., D. Palmer, and R. Sheldrake. 2017. Priorities for Australia's biosecurity system: an independent review of the capacity of the national biosecurity system and its underpinning Intergovernmental Agreement. Commonwealth of Australia, Canberra, Australia.

Crona, B. I. and J. N. Parker. 2012. Learning in support of governance: theories, methods, and a framework to assess how bridging organizations contribute to adaptive resource governance. Ecology and Society 17(1):32. https://doi. org/10.5751/ES-04534-170132

Curnock, M., C. Farbotko, K. Collins, C. J. Robinson, and K. Maclean. 2017. Engaging with risk (or not): shared responsibility for biosecurity surveillance and the role of community gardens. Geographical Research 55(4): 379-394. https://doi. org/10.1111/1745-5871.12231

Curtis, A., H. Ross, G. R. Marshall, C. Baldwin, J. Cavaye, C. Freeman, A. Carr, and G. J. Syme. 2014. The great experiment with devolved NRM governance: lessons from community engagement in Australia and New Zealand since the 1980s. Australasian Journal of Environmental Management 21 (2):175-199. https://doi.org/10.1080/14486563.2014.935747

Davidson, J., and M. Lockwood. 2009. Interrogating devolved natural resource management: challenges for good governance. Pages 75-89 in M. Lane, C. Robinson, and B. Taylor, editors. Contested country: regional natural resource management in Australia. CSIRO, Melbourne, Australia. https://doi. org/10.1071/9780643098015
De Chazal, J. 2008. Biosecurity: improving detection by enlisting community detectives. The Cairns Cafe Report. The Australian Centre of Excellence for Risk Analysis, Canberra, Australia.

D'Emden, F., G. Bell, and R. Llewellyn. 2004. Rural landowner attitudes towards the responsibilities and action for managing declared weeds in Western Australia. Plant Protection Quarterly 19:147-150.

Department of Agriculture. 2021. Report a pest or disease concern. Department of Agriculture, Australian Government, Canberra City, Australia. [online] URL: https://www.agriculture.gov.au/ pests-diseases-weeds/report

Donaldson, A. 2008. Biosecurity after the event: risk politics and animal disease. Environment and Planning A: Economy and Space 40(7):1552-1567. https://doi.org/10.1068/a4056

Doran, E. 2009. At hospitality's threshold: from social inclusion to exilic education. Curator 52(2):169-182. https://doi. org/10.1111/j.2151-6952.2009.tb00342.x

Doubleday, N. 2007. Culturing adaptive co-management: finding 'keys' to resilience in asymmetries of power. Pages 228-248 in D. Armitage, F. Berkes, and N. Doubleday, editors. Adaptive comanagement: collaboration, learning and multi-level governance. UBC Press, Vancouver, British Columbia, Canada.

Dreyer, M., M. Boström, and A. M. Jönsson. 2014. Participatory deliberation, risk governance and management of the marine region in the European Union. Journal of Environmental Policy \& Planning 16(4):497-515. https://doi.org/10.1080/1523908X.2013.866891

Edwards, F., J. Dixon, and R. Beilin. 2018. Adopting a public health ecology approach to a key food security issue: apiary, biodiversity and conservation. Pages 1075-1089 in T. Marsden, editor. The SAGE handbook of nature. SAGE, London, UK. https://doi.org/10.4135/9781473983007.n56

Enticott, G. 2014. Relational distance, neoliberalism and the regulation of animal health. Geoforum 52:42-50. https://doi. org/10.1016/j.geoforum.2013.12.004

Falk, I., K. Surata, and K. Suwondo. 2008. Community management of biosecurity: overview of some Indonesian studies. International Journal of Learning in Social Contexts 2:1-29.

Folke, C., T. Hahn, P. Olsson, and J. Norberg. 2005. Adaptive governance of social-ecological systems. Annual Review of Environment and Resources 30:441-473. https://doi.org/10.1146/ annurev.energy.30.050504.144511

Gadgil, M., F. Berkes, and C. Folke. 1993. Indigenous knowledge for biodiversity conservation. Ambio 22(2-3):151-156.

Gilmour, J., R. Beilin, T. Sysak, and M. Hernández-Jover. 2017. Getting the message right: tools for improving biosecurity risk communication. Pages 206-228 in A. P. Robinson, T. Walshe, M. A. Burgman, and M. Nunn, editors. Invasive species: risk assessment and management. Cambridge University Press, Cambridge, UK. https://doi.org/10.1017/9781139019606.010

Graham, S. 2013. Three cooperative pathways to solving a collective weed management problem. Australasian Journal of 
Environmental Management 20(2):116-129. https://doi. org/10.1080/14486563.2013.774681

Graham, S., A. L. Metcalf, N. Gill, R. Niemiec, C. Moreno, T. Bach, V. Ikutegbe, L. Hallstrom, Z. Ma, and A. Lubeck. 2019. Opportunities for better use of collective action theory in research and governance for invasive species management. Conservation Biology 33(2):275-287. https://doi.org/10.1111/cobi.13266

Guba, E. G., and Y. S. Lincoln. 1998. Competing paradigms in qualitative research. Pages 105-117 in N. K. Denzin and Y. S. Lincoln, editors. The landscape of qualitative research: theories and issues. SAGE, Thousand Oaks, California, USA.

Gunderson, L. H., and C. S. Holling. 2002. Panarchy: understanding transformations in human and natural systems. Island, Washington, D.C., USA.

Hamilton, M. 2014. The 'new social contract' and the individualisation of risk in policy. Journal of Risk Research 17 (4):453-467.

Hardt, M., and A. Negri. 2009. Commonwealth. Harvard University Press, Cambridge, Massachusetts, USA. https://doi. org/10.2307/j.ctvjsf48h

Harrington, C., A. Curtis, and R. Black. 2008. Locating communities in natural resource management. Journal of Environmental Policy \& Planning 10(2):199-215. https://doi. org/10.1080/15239080801928469

Head, L., and P. Muir. 2004. Nativeness, invasiveness, and nation in Australian plants. Geographical Review 94(2):99-217. https:// doi.org/10.1111/j.1931-0846.2004.tb00167.x

Hester, S. M., and O. J. Cacho. 2017. The contribution of passive surveillance to invasive species management. Biological Invasions 19:737-748. https://doi.org/10.1007/s10530-016-1362-4

Higgins, V., M. Bryant, M. Hernández-Jover, C. McShane, and L. Rast. 2016. Harmonising devolved responsibility for biosecurity governance: the challenge of competing institutional logics. Environment and Planning A: Economy and Space 48 (6):1133-1151. https://doi.org/10.1177/0308518X16633471

Higgins, V., M. Bryant, M. Hernández-Jover, L. Rast, and C. McShane. 2018. Devolved responsibility and on-farm biosecurity: practices of biosecure farming care in livestock production. Sociologia Ruralis 58(1):20-39. https://doi. org/10.1111/soru.12155

Higgins, V., and J. Dibden. 2011. Biosecurity, trade liberalisation, and the (anti)politics of risk analysis: the Australia - New Zealand apples dispute. Environment and Planning A: Economy and Space 43(2):393-409. https://doi.org/10.1068/a43289

Holling, C. S., and G. K. Meffe. 1996. Command and control and the pathology of natural resource management. Conservation Biology 10(2):328-337. https://doi.org/10.1046/j.1523-1739.1996.10020328. $\underline{\mathrm{X}}$

Jalbert, K., and A. J. Kinchy. 2016. Sense and influence: environmental monitoring tools and the power of citizen science. Journal of Environmental Policy \& Planning 18(3):379-397. https:// doi.org/10.1080/1523908X.2015.1100985
Jasanoff, S., M. L. Martello, and P. Haas, editors. 2004. Earthly politics: local and global in environmental governance. MIT Press, Cambridge, Massachusetts, USA.

Kompas, T., L. Chu, P. Van Ha, and D. Spring. 2019. Budgeting and portfolio allocation for biosecurity measures. Australian Journal of Agricultural and Resource Economics 63(3):412-438. https://doi.org/10.1111/1467-8489.12305

Kruger, H., N. Stenekes, R. Clarke, and A. Carr. 2010. Biosecurity engagement guidelines: practical advice for involving communities. Commonwealth of Australia, Canberra, Australia.

Kruger, H., L. Thompson, R. Clarke, N. Stenekes, and A. Carr. 2009. Engaging in biosecurity: gap analysis. Commonwealth of Australia, Canberra, Australia.

Lavau, S. 2011. The nature/s of belonging: performing an authentic Australian river. Ethnos 76(1):41-64. https://doi. org/10.1080/00141844.2010.537758

Leach, M., and I. Scoones. 2007. Mobilising citizens: social movements and the politics of knowledge citizenship. DRC Synthesis Paper IDS Working Paper 276. Institute of Development Studies, Brighton, UK. [online] URL: https://www. ids.ac.uk/download.php?file=files/Wp276.pdf

Lebel, L., J. M. Anderies, B. Campbell, C. Folke, S. HatfieldDodds, T. P. Hughes, and J. Wilson. 2006. Governance and the capacity to manage resilience in regional social-ecological systems. Ecology and Society 11(1):19. https://doi.org/10.5751/ ES-01606-110119

Lockwood, M., J. Davidson, A. Curtis, E. Stratford, and R. Griffith. 2010. Governance principles for natural resource management. Society and Natural Resources 23(10):986-1001. https://doi.org/10.1080/08941920802178214

Ludwig, D., M. Mangel, and B. Haddad. 2001. Ecology, conservation, and public policy. Annual Review of Ecological Systems 32:481-517. https://doi.org/10.1146/annurev. ecolsys.32.081501.114116

Maller, C., R. Kancans, and A. Carr. 2007. Biosecurity and small landholders in peri-urban Australia. Commonwealth of Australia, Canberra, Australia.

Matthews, K. 2011. A review of Australia's preparedness for the threat of foot-and-mouth disease. Commonwealth of Australia, Canberra, Australia. [online] URL: https://www.agriculture.gov. au/pests-diseases-weeds/animal/fmd/review-foot-and-mouth-disease

McLennan, B., and J. Handmer. 2014. Changing the rules of the game: mechanisms that shape responsibility-sharing from beyond Australian fire and emergency management. Australian Journal of Emergency Management 27(2):1-13.

Mendham, E., and A. Curtis. 2010. Taking over the reins: trends and impacts of changes in rural property ownership. Society \& Natural Resources 23(7):653-668. https://doi.org/10.1080/08941$\underline{920801998893}$

Nairn, M. E., P. G. Allen, A. R. Inglis, and C. Tanner. 1996. Australian quarantine: a shared responsibility. The government response. Department of Primary Industries and Energy, Commonwealth of Australia, Canberra, Australia. 
Newman, L. L., and A. Dale. 2005. Network structure, diversity, and proactive resilience building: a response to Tompkins and Adger. Ecology and Society 10(1):r2. https://doi.org/10.5751/ ES-01396-1001r02

Nordblom, T., M. Smyth, A. Swirepik, A. Sheppard, and D. Briese. 2001. Benefit-cost analysis for biological control of Echium weed species (Paterson's curse/Salvation Jane). Contributed paper, 45th Annual Conference of the Australian Agricultural and Resource Economics Society (AARES), Adelaide, 23-25 January 2001.

Olsson, P., L. H. Gunderson, S. R. Carpenter, P. Ryan, L. Lebel, C. Folke, and C. S. Holling. 2006. Shooting the rapids: navigating transitions to adaptive governance of social-ecological systems. Ecology and Society 11(1):18. https://doi.org/10.5751/ES-01595-110118

Österblom, H., and C. Folke. 2013. Emergence of global adaptive governance for stewardship of regional marine resources. Ecology and Society 18(2):4. https://doi.org/10.5751/ES-05373-180204

Palmer, S., M. Sully, and F. Fozdar. 2009. Farmers, animal disease reporting and the effect of trust: a study of West Australian sheep and cattle farmers. Rural Society 19:32-48. https://doi. org/10.5172/rsj.351.19.1.32

Paschen, J.-A., and R. Beilin. 2015. 'Avoiding the certainty trap': a research programme for the policy-practice interface. Environment and Planning C: Government and Policy 33 (6):1394-1411. https://doi.org/10.1068/c13321

Perrone, S. T., and S. Malfroy. 2014. BeeForce Australia Part II. Bee World 91(3):70-74. https://doi.org/10.1080/0005772X.2014.11417609

Phillips, C. 2013. Living without fruit flies: biosecuring horticulture and its markets. Environment and Planning A: Economy and Space 45(7):1679-1694. https://doi.org/10.1068/ $\underline{\mathrm{a} 45274}$

Phillips, C. 2014. Following beekeeping: more-than-human practice in agrifood. Journal of Rural Studies 36:149-159. https:// doi.org/10.1016/j.jrurstud.2014.06.013

Phoenix, C., N. J. Osborne, C. Redshaw, R. Moran, W. StahlTimmins, M. H. Depledge, L. E. Fleming, and B. W. Wheeler. 2013. Paradigmatic approaches to studying environment and human health: (forgotten) implications for interdisciplinary research. Environmental Science and Policy 25:218-228. https:// doi.org/10.1016/j.envsci.2012.10.015

Piper, C. 2020. Bushfires: is the 2019/2020 bushfire season a portent for the future? Interaction 48(1):17-23.

Pritchard, L., and S. Sanderson. 2002. The dynamics of political discourse in seeking sustainability. Pages 147-169 in L. H. Gunderson and C. S. Holling, editors. Panarchy: understanding transformations in human and natural systems. Island, Washington, D.C., USA.

Rabinow, P., and N. Rose. 2006. Biopower today. BioSocieties 1:195-217. https://doi.org/10.1017/S1745855206040014

Rawluk, A., R. Beilin, H. Bender, and R. Ford. 2020. Practices in social ecological research: interdisciplinary collaboration in 'adaptive doing.' Palgrave Macmillan, London, UK. https://doi. org/10.1007/978-3-030-31189-6

Reed, M. S., and R. Curzon. 2015. Stakeholder mapping for the governance of biosecurity: a literature review. Journal of Integrative Environmental Sciences 12(1):15-38. https://doi. org/10.1080/1943815X.2014.975723

Reid, K., R. Beilin, and J. McLennan. 2020. Communities and responsibility: narratives of place-identity in Australian bushfire landscapes. Geoforum 109:35-43 https://doi.org/10.1016/j. geoforum.2019.12.015

Reo, N. J., K. Whyte, D. Ranco, J. Brandt, E. Blackmer, and B. Elliott. 2017. Invasive species, indigenous stewards, and vulnerability discourse. American Indian Quarterly 41(3):201-223. https://doi.org/10.5250/amerindiquar.41.3.0201

Richards, C., and V. Higgins. 2016. Trade liberalisation and Australian biosecurity: opportunities and challenges under the 'shared responsibility' approach. Farm Policy Journal 13(3):1-9.

Sharp, E. A., R. Thwaites, A. Curtis, and J. Millar. 2013. Factors affecting community-agency trust before, during and after a wildfire: an Australian case study. Journal of Environmental Management 130:10-19. https://doi.org/10.1016/j.jenvman.2013.08.037

Simpson, M., and V. Srinivasan. 2014. Australia's biosecurity future: preparing for future biological challenges. CSIRO, Canberra, Australia.

Sinclair, K., A. Curtis, and P. Freeman. 2020. Biosecurity in multifunctional landscapes: challenges for approaches based on the concept of 'shared responsibility.' Preventive Veterinary Medicine 178:104682. https://doi.org/10.1016/j.prevetmed.2019.04.011

Spring, D., and T. Kompas. 2015. Managing risk and increasing the robustness of invasive species eradication programs. Asia \& the Pacific Policy Studies 2(3):485-493. https://doi.org/10.1002/ app5.105

Star, S. L. 2010. This is not a boundary object: reflections on the origin of a concept. Science, Technology, \& Human Values 35 (5):601-617. https://doi.org/10.1177/0162243910377624

Tidemann, C. R., and M. J. Vardon. 1997. Pests, pestilence, pollen and pot roasts: the need for community based management of flying foxes in Australia. Australian Biologist 10(1):77-83.

Van Assche, K., R. Beunen, M. Duineveld, and M. Gruezmacher. 2017. Power/knowledge and natural resource management: Foucaultian foundations in the analysis of adaptive governance. Journal of Environmental Policy \& Planning 19(3):308-322. https:// doi.org/10.1080/1523908X.2017.1338560

Walker, B. H., and D. Salt. 2006. Resilience thinking: sustaining ecosystems and people in a changing world. Island, Washington, D.C., USA.

Wallington, T. J., and G. Lawrence. 2008 Making democracy matter: responsibility and effective environmental governance in regional Australia. Journal of Rural Studies 24:277-290. https:// doi.org/10.1016/j.jrurstud.2007.11.003 
Welsh, M. 2014. Resilience and responsibility: governing uncertainty in a complex world. Geographical Journal 180 (1):15-26. https://doi.org/10.1111/geoj.12012

West, S., L. J. Haider, S. Stålhammar, and S. Woroniecki. 2020. A relational turn for sustainability science? Relational thinking, leverage points and transformations. Ecosystems and People 16 (1):304-325. https://doi.org/10.1080/26395916.2020.1814417

West, S., L. van Kerkhoff, and H. Wagenaar. 2019. Beyond "linking knowledge and action": towards a practice-based approach to transdisciplinary sustainability interventions. Policy Studies 40(5):534-555. https://doi.org/10.1080/01442872.2019.1618810

Woodhill, J. 2010. Sustainability, social learning and the democratic imperative: lessons from the Australian Landcare movement. Pages 57-72 in C. Blackmore, editor. Social learning systems and communities of practice. Springer, London, UK. https://doi.org/10.1007/978-1-84996-133-2_4 